\title{
EL CENTRO PENITENCIARIO DEL ESTADO DE MEJICO
}

1. El contexto nacional. Para la comprensión cabal de lo que signif́ica el Centro Penitenciario del Estado de México en el penitenciarismo de este país, en forma tal que sea posible valorar su naturaleza y proyecciones, es pertinente situarlo dentro de un doble conjunto de circunstancias: por una parte, la situación histórica y actual del régimen de ejecución de penas privativas de libertad en México; por otra parte, el conjunto de medidas y sistemas para el tratamiento de los delincuentes adoptados y puestos en marcha, en un periodo inferior a tres años, durante la presente administración del Gobernador, Lic. Juan Fernández Albarrán, quien ha realizado una verdadera revolución en el sistema de ejecución de penas.

Una y otra vez, en reiteración sin pausa, se ha insistido en apuntar el desastroso estado de las prisiones mexicanas y la imperiosa necesidad de reformarlas. Ya Fray Jerónimo de Mendieta calificó a nuestras cárceles de "jaulas" e "inhumanas", y el ministro Llave, en un mensaje dirigido al Congreso de la República en 1823, describió el pésimo estado de los reclusorios. Refiriéndose a la Cárcel de Corte que funcionó en la ciudad de México desde principios del siglo XIX, Peña indicó que era "verdadero barrio de los milagros en París, una sentina inmunda de miseria". También en el siglo pasado, Mariano Otero, uno de los grandes creadores del amparo, observó: "Nuestro sistema de prisiones es la combinación más diestra que el genio del mal hubiera podido inventar para pervertir a los hombres". La promiscuidad y la indisciplina en las prisiones fueron puestas de manifiesto por Antonio Martínez de Castro, principal redactor del Código Penal de 1871. Demetrio Sodi puntualizó algunos de los nefastos resultados del sistema implantado en la Penitenciaria del Distrito. José Natividad Macías, diputado constituyente que sufrió prisión en esta Penitenciaría, exclamó sobre ella, en 1917, "que es fatal, infernal, detestable, que merece que se destruya, aunque se pierdan los millones que se gastaron". Franco Sodi, episódico director de la actual Cárcel Preventiva de la ciudad de México, escribió: "Nuestras cárceles, como tanto se ha repetido, son centros de infamia, escuelas de crimen, escaparates donde se exhiben todas las miserias físicas y morales imaginables, ejemplos de indisciplina, mercados en los que operan próspera e impunemente los traficantes del vicio”. Según Quiroz Cuarón, “nuestras prisiones corresponden a la prisión cloaca, a lugares de corrupción total, que degradan y embrutecen al hombre". (1)

El desalentador panorama trazado a lo largo de un siglo evoca, fuertemente, las descripciones de cárceles que hiciera el infatigable e insigne penitenciarista inglés John Howard, en su obra, publicada en 1777, acerca del estado de las prisiones en Inglaterra y Gales, con observaciones preliminares e informe sobre algunas prisiones extranjeras. La situación nacional en este terreno no se modificó, a pesar de las normas contenidas en la Constitución Federal de 1857 (en que se conservó la pena de muerte, sin perjuicio de abolirla cuando el país contara con un genuino

1 Acerca de estos comentarios y de la situación penitenciaria de México, ofr. nuestros trabajos Represión y Tratamiento Penitenciario de Criminales (México, 1962), pp. 212-218, y El Artículo 18 Constitucional (UNAM, la. edición, México, 1967), pp. 66-69. Véase también la síntesis de Porte Petit en su discurso de clausura del Congreso Nacional Penitenciario de 1952, en Conclusiones del Congreso Nacional Penitenciario (Biblioteca Jurídica, Ediciones del Gobierno del Estado de México, volumen IV, Toluca, 1953), pp 21-27. 
sistema penitenciario) y en la de 1917, reformada en 1964-1965, para perfeccionar las disposiciones acerca de ejecución de penas. (2).

2. El contexto estatal. Situemos ahora al Centro Penitenciario dentro de su circunstancia, a la luz del novisimo sistema de tratamiento de los delincuentes implantado en el Estado de México y sin igual, hasta ahora, en nuestro pais, tanto por lo que respecta al plano federal como por lo que toca a los estatales.

a) El 23 de abril de 1966 se expidió la Ley de Ejecución de Penas Privativas y Restrictivas de Libertad del Estado de México. (3)

b) El 19 de enero de 1967 se puso en marcha el Centro Penitenciario del Estado, en una fase de programación y preparación que culminó el 15 de junio del mismo año, fecha en que ingresaron a este Centro sus primeros reclusos.

c) El 30 de diciembre de 1967 se promulgó la Ley de Rehabilitación de Menores, que junto con el Código Tutelar de Menores, de Michoacán, constituye el más moderno Derecho mexicano referente a menores infractores.

d) A principios de 1968 inició sus funciones la Escuela de Rehabilitación, creada para instrumentar, en

2 Sobre el problema durante los debates del Congreso Constituyente de 1856-1857, cfr. Zarco, Historia del Congreso Extraordinario Constituyente de 1856 y 1857 (Talleres de "La Ciencia Jurídica", México, 1899), t. III, pp. 271, 406-407, 456-465. Acerca de los debates en 1916-1917, crf. Diario de los Debates del Congreso Constituyente (México, 1922), t. I, pp. 644-667 y 698 , y t. II pp. 36-55. En cuanto a las reformas de 1964-1965, nos remitimos a la síntesis hecha en nuestro citado volumen, El Artículo 18 Constitucional, pp. 53-62.

3 En la actualidad sólo los Estados de Veracruz (1947) y Sonora (1948) poseen ordenamientos semjeantes, en tanto que el Distrito Federal carece de él, no obstante los diversos proyectos formulados. Para el Distrito Federal, han existido, por lo menos, cuatro proyectos: de Abarca, de Vela, de Porte Petit-Quiroz Cuarón-Fernández Doblado, y de una comisión presidida por el mismo Porte Petit. Este último proyecto, de 1967, es el más reciente. Además, existe un proyecto de Código de Ejecución de Penas para el Estado de Michoacán, de Gilberto Vargas López. Acerca de la Ley para el Estado de México, crf. García Ramírez, Nuestra más reciente Ley Ejecutiva Penal. Derecho Penal Contemporáneo, 1968, No. 24, pp. 15-36. la práctica, el tratamiento de los menores infractores.

e) En mayo de 1968 se instauró, por vez primera en la república mexicana, en el Centro Penitenciario, el tratamiento preliberacional intenso postulado por el Segundo Congreso de las Naciones Unidas sobre Prevención del Delito y Tratamiento de los Delincuentes (Londres, 1960), a base de permisos de salida de fin de semana. (4)

f) El 15 de julio de 1968 comenzó la construcción del primer establecimiento penal abierto de la república mexicana, anexo al Centro Penitenciario y diseñado conforme a las más avanzadas recomendaciones técnicas acerca de este tipo de establecimientos, desconocidos en la práctica penitenciaria mexicana, no obstante haber surgido desde 1891 en Witswill, Sui$z a$, extendiéndose posteriormente a numerosos países en todos los continentes, con excelentes resultados, de los que da testimonio - por ejemplo- el hecho de que tan sólo en New South Wales, Australia, existen alrededor de veinte instituciones abiertas.

g) El 5 de julio de 1968 quedó constituído y reglamentado el Patronato para Liberados, con participación de representantes gubernamentales, del sector privado (empresarios, obreros, propietarios del campo y campesinos), de la prensa y de organismos profesionales: Academia Mexicana de Ciencias Penales y Colegio de Abogados del Estado de México. (5)

h) El 13 de agosto de 1968, el Congreso local aprobó el establecimiento del sistema de remisión parcial de penas, original para México y que ofrece, inclusive, aspectos novedosos para los demás países. La redención de penas por el trabajo existe en España y Bulgaria; en España, a través del artículo 100 del

4 El Congreso sostuvo que el tratamiento preliberacional forma parte del adiestramiento y tratamiento generales a que se debe someter al recluso. Como formas de aquél, citó, entre otras: permisos de salida de duración variable y autorizaciones para trabajar fuera de la institución. Cfr. Second United Nations Congress on the Pevention of Crime and the Treatment of Offenders. Report prepared by the Secretariat (United Nations, New York, A/CONF. 17/20), p. 64.

5 Sobre el tema, cfr. nuestro trabajo Asistencia a Reos Liberados (Ed. Botas, 1a. edición, México, 1966). Además del Patronato del Estado de México, hoy día funcionan en el país el del Distrito Federal (el primero de todos, regulado por el reglamento de 5 de julio de 1963) y el del Estado de Puebla. 
Código Penal, la orden de 24 de febrero de 1945 y el Reglamento del Servicio de Prisiones; en Bulgaria, merced al arículo 23 del Código penal de 1951. En ambos países (así como en el Estado de Zacatecas, en México, desde 1956) se bonifica a los reclusos de buena conducta un día de prisión por cada dos de trabajo. En el Estado de México, en cambio, además de trabajo y buena conducta se requieren participación en actividades educativas y, lo que es más importante, porque apareja un juicio profundo de personalidad, la resocialización del reo, en forma tal que no presente peligrosidad social (6)

3) Sistema penitenciario. Conforme a la Ley de Ejecución de Penas y a los reglamentos internos, en el Centro Penitenciario se sigue el sistema progresivo técnico. Progresivo, porque se divide en etapas (7), a saber: de estudio y diagnóstico, de tratamiento -a su vez subdividida en fase de tratamiento en clasificación, preliberación y semilibertad- y de reintegración. Técnico, porque se apoya en el estudio individual de los reclusos (8). El estudio individual se realiza en la fase de observación, una vez que el

6 Existen otros antecedentes, más o menos remotos, de este sistema, consistentes en conmutación o reducción de pena con base en el arrepentimiento y la enmienda del recluso, conforme al Código penal español de 1822, de donde pasaron al proyecto de Código penal para el Estado de México, de 1831, y al Código penal de Veracruz, de 1834.

7 Montesinos, Maconochie y Crofton fueron los fundadores en este campo. Sin embargo, la prioridad cronológica corresponde al coronel español Montesinos, quien introdujo el régimen progresivo en el presidio de San Agustín, en Valencia, en 1835. En torno a estos temas, son fundamentales para la bibliografía en español las obras de Cuello Calón, La Moderna Penología (BOSCH, Barcelona, 1958), Ruiz Funes, La Crisis de la Prisión (Jesús Montero, editor, La Habana, 1949) y Bernaldo de Quirós, Lecciones de Derecho Penitenciario (UNAM, México, 1953).

8 Ambito en el que fueron creadores, además del ilustre César Lombroso, el argentino José Ingenieros y el belga Vervaeck, instituyendo en 1907, en sus respectivos países, laboratorios de antropología penitenciaria. De esta forma se extendió hacia diversos continentes la obra iniciada por Lombroso en Pésaro. Vervaeck instaló su laboratorio en la prisión de Minimes, en noviembre de 1907, en tanto que el filósofo y criminólogo latinoamericano Ingenieros fundó el Instituto de Criminología de la Penitenciaría de Buenos Aires el 6 de junio de 1907. sujeto ha sido sentenciado, para precisar su tratamien. to. Este sistema, que permite en todo momento la actualización de estudios y la modificación del tratamiento, se inspira en experiencias similares bien conocidas, como las del Centro de Observación de Rebibbia, en Italia, y los Centros de Recepción de los Estados Unidos. El estudio individual y el tratamiento, cuyos resultados se consignan en un expediente "tipo" en México, dividido en las secciones pertinentes, abarca los aspectos médico general y criminológico, psiquiátrico, psicológico, socioeconómico, laboral y pedagógico.

Es indispensable mencionar que en el Centro Penitenciario del Estado de México funciona, también por vez primera en nuestro país, un Consejo Técnico similar a los comités de clasificación de algunas prisiones norteamericanas, organismo que examina en sesiones semanales de clínica criminológica los casos individuales y asuntos de interés general para la institución. Dicho Consejo está integrado por los siguientes funcionarios: director, subdirector, jefe y subjefe de vigilancia, administrador, supervisor de trabajo, jefe del servicio médico, médico interno, psiquiatra, psicólogos, trabajadores sociales y jefe de instrucción. A las sesiones concurren, sistemáticamente, expertos y asesores ajenos al personal del Centro Penitenciario; generalmente se trata de penalistas, criminólogos y psiquiatras distinguidos, con amplio conocimiento de los problemas penitenciarios.

Una de las principales bases del sistema penitenciario en general y del tratamiento de los reclusos, es la clasificación de éstos, cuyos lineamientos fundamentales están consignados en el artículo 18 de la Constitución Federal. Asi, existen dependencias completamente separadas para procesados y sentenciados, varones y mujeres. Los servicios generales para estas últimas se encuentran, a su vez, separados de los correspondientes a varones. No obstante que la actual capacidad del Centro Penitenciario es de 800 personas, en ningún momento ha excedido la población de 600 reclusos en total, ni de 300 en los sectores de procesados y sentenciados, respectivamente. Con ello se acogen las recomendaciones contemporáneas de la ciencia penitenciaria, que prefiere establecimientos correccionales pequeños, donde es posible llevar a cabo un verdadero tratamiento individualizado, y además se protege la clasificación, que sería imposible si se saturara o rebasara la capacidad de alojamiento del Centro. 
La clasificación interna, independientemente de la que se apoya en situación jurídica y sexo, atiende a los siguientes criterios: antecedentes penales (por pabellones), peligrosidad y conducta (por pabellones), delito cometido (por secciones) y edad del sujeto (por celdas). Para los efectos de alojamiento clasificado, el Centro Penitenciario cuenta con pabellones de clasificación, tanto en el sector de procesados como en el de sentenciados, con un pabellón de observación y con un pabellón de tratamiento en segregación.

Por lo que respecta al tratamiento preliberacional, que se extiende a reclusos a quienes falte, salvo casos excepcionales, no más de un año para obtener libertad absoluta o condicional (on parole), en el curso de cuatro meses se han concedido cerca de cien permisos de salida de fin de semana, sin que se haya presentado ninguna evasićn. Los beneficiados con estos permisos laboran en la construcción del establecimiento abierto y son, automáticamente, candidatos a residir en esta nueva institución, en régimen de semilibertad.

4. Elementos para el tratamiento. En los 113,985 metros cuadrados que el Centro Penitenciario abarca, se encuentran las instalaciones materiales que son el sustento físico del tratamiento, fundado en las Reglas Minimas para el Tratamiento de los Reclusos aprobadas por el Primer Congreso de las Naciones Unidas sobre Prevención del Delito y Tratamiento de los Delincuentes (Ginebra, 1955). (9)

La atención médica es general, que comprende asimismo la odontológica y psiquiátrica, que engloba al departamento de psicología. Además de los consultorios necesarios para estos servicios, la clínica del

9 Un panorama sobre los diversos aspectos del Centro Penitenciario se puede ver en la revista "Criminalia" de la Academia Mexicana de Ciencias Penales (año XXXIV, 1968, $\mathrm{N}^{9} 5$ ), a través de los siguientes trabajos: Fernández Albarrán, El Centro Penitenciario del Estado de México (pp. 232-234); Garrido, La Penitenciaría del Estado de México (pp. 235-236); García Ramírez, Hacia la reforma penitenciaria en México: el Centro Penitenciario del Estado de México (pp. 237-247); Sánchez Galindo, Constitución de un grupo piloto (pp. 248-254); Gutiérrez Quinto y Cedillo Ortiz, Selección de personal de vigilancia (pp. 255-260); Gómez Núñez, El trabajo (pp. 2161 -267); Vázquez Chávez, La educación (pp. 268271); Vilchis Hernández y Monares García, El Servicio médico (pp. 272-275); y Díaz Ortiz y Duvigman Flores, El trabajo social (pp. 276-279).
Centro cuenta con salas para enfermos que deben permanecer aislados, así como con recámaras para el médico de guardia (el servicio se presta ininterrumpidamente) y la enfermera de guardia.

La oficina de trabajo social, cuyo principal cometido es el establecimiento, mantenimiento y mejoramiento, en su caso, de las relaciones del recluso con personas convenientes del exterior, controla la visita familiar personal, que se recibe en una sala especial y en un jardín anexo, y la visita intima, que se concede al recluso, en forma también semanal, con su esposa $o$, en caso de no haber matrimonio (situación frecuentísima en ciertos sectores de la población mexicana), con la mujer con quien ha tenido unión concubinaria estable, similar a la matrimonial. Jamás se concede visita íntima con prostitutas o amigas ocasionales. Tanto la visitante como el visitado son sometidos a cuidadosos exámenes clínicos y de laboratorio, para descartar la existencia de enfermedades trasmisibles, especialmente venéreas.

La educación no abarca simplemente la enseñanza académica primaria, que tiene carácter obligatorio en el pais, sino también ha sido planeada y se aplica con clara conciencia del tipo especial de alumnado al que está dirigida. Así pues, la educación asume también estas otras perspectivas: ética, social, artística, física, higiénica y laboral. Para ello, se cuenta con el concurso de profesores especializados en tratamiento de infractores en la Escuela Normal de Especialización. Para el cumplimiento de las tareas educativas, a las que están inmediatamente conectadas las recreativas, se cuenta con la escuela "Sor Juana Inés de la Cruz", la biblioteca "Angel María Garibay" y el auditorio "Ignacio Ramírez", que tiene 420 butacas. Además, existen campos para la práctica de fútbol, básquetbol, vóleibol y atletismo.

En el renglón de trabajo, que es constitucionalmente obligatorio para los sentenciados (10), es oportu-

$10 \mathrm{La}$ obligatoriedad del trabajo para los sentenciados se colige de la interpretación correlacionada de los artículos $5^{\circ}$ y $18^{\circ}$ constitucionales; aquel, en la medida en que establece que sólo será obligatorio el trabajo penal, y el segundo, en cuanto prescribe que la readaptación social se obtendrá con base en el trabajo, entre otros elementos. Es errónea, pues, la información contenida en el estudio Trabajo Penitenciario, de las Naciones Unidas (Nueva York, $1955 \mathrm{ST} / \mathrm{SOA} / \mathrm{SO} / 5)$, p. 2, donde se indica que México no considera el trabajo de penados como una 
no mencionar que la asignación a labores se hace tomando en cuenta los deseos, aptitudes, capacidad y necesidades del recluso. En el Centro Penitenciario tienen ocupación útil y remunerada todos los internos sentenciados, proporción insólita en la práctica penitenciaria mexicana. Las áreas de trabajo son: a) industrial y semiindustrial (fábricas de mosaicos, tabique y tubo, carpinteria, sastreria y tapiceria); b) agrícola (hortalizas y jardinería); c) pecuaria (cunicultura y porcicultura); d) de servicios (cocina, panadería, lavandería. tortilleria y mantenimiento); e) artesanal (artículos tejidos de lana, algodón o palma, y trabajos de madera incrustada); y f) comisiones (auxiliares en biblioteca, espectáculos, etc., pero no en funciones administrativas ni autoritarias).

El principal mercado de la producción es el gubernamental. El salario tiene este destino reglamentario. $50 \%$ para la familia del recluso, $20 \%$ para la reparación del daño causado por el delito, 10\% para la formación de un fondo de ahorros del recluso (para ello, se han abierto cuentas de ahorro a cada interno en una institución bancaria; los intereses se acreditan en favor del recluso), $10 \%$ para sostenimiento de la institución y $10 \%$ para gastos menores del interno.

5. Docencia e investigación. El Centro Penitenciario funciona también como instituto de docencia $e$ investigación. Aquella se imparte principalmente (aunque no exclusivamente, pues también ha cubierto a alcaides de cárceles distritales y a profesores destinados a la escuela del Centro) a los miembros del cuerpo de vigilancia, en diversas disciplinas: jurídicas, sociales, naturales y prácticas. Al respecto, es oportuno apuntar que en la república mexicana no existe, desde 1951, ninguna escuela para personal de prisiones, por lo que el Centro Penitenciario se vio en la necesidad de implantar su propio sistema de docencia (11). Además - cosa inusitada en el país- se hi-

obligación, sino como un derecho. "La Constitución de México garantiza explícitamente a los reclusos el derecho a trabajar sin que sea una obligación $y$, a este respecto, México es un caso único entre los Estados que suministran información sobre el particular" ibídem).

11 La escuela de capacitación del personal de prisiones, cuyo currículum comprendía tres años de estudios, se abrió en 1949, bajo los auspicios de la Universidad Nacional Autónoma de México, que confío la dirección de la escuela a la penitenciarista española Victoria Kent. En el Centro Penitenciario se zo selección técnica de los aspirantes a celadores aplicando baterias de tests psicológicos a cada candidato: entrevista, Paven, Machover, Rorschach y Bender.

El Centro Penitenciario ofrece fértil campo a la investigación, considerando la variada criminalidad del Estado de México, donde existen tanto sectores altamente industrializados, como zonas de agricultura rudimentaria. Se han desarrollado investigaciones (cuyos resultados no podríamos consignar ahora, dada la breve extensión de este trabajo, eminentemente descriptivo) acerca de tendencia y ritmo de los delitos (es impresionante observar el fuerte predominio de los de violencia entre reclusos del Centro: homicidio y parricidio: $41.72 \%$, lesiones: $8.14 \%$, y violación: $11.3 \%$ ), biotipología de los delincuentes y léxico delincuencial. En la actualidad se está llevando a cabo una investigación sobre genética, en forma semejante a las investigaciones efectuadas entre delincuentes recluidos en prisiones de Inglaterra, con intervención de médicos especialistas del Departamento de Genética del Hospital de Pediatria correspondiente al Centro Médico Nacional del Instituto Mexicano del Seguro Social. (12)

6. Comentarios. En este último apartado de nuestro trabajo nos limitaremos a transcribir, en apretada sín-

ha diversificado la naturaleza de los cursos permanentes y periódicos: se comprenden desde conferencias sobre peligrosidad y agresividad, hasta cursiIlos intensivos en torno a problemas de relaciones industriales, organizados, estos últimos, en coordinación con el Centro Nacional de Productividad.

12 Ante los porcentajes de delitos violentos, muy elevados $\sin$ duda, resulta reducido el $21.19 \%$, proporción que alcanzan, sumados, los responsables de robo, abigeato, fraude, daño en propiedad ajena, despojo y abuso de confianza. De 275 sentenciados, 50 lo estaban a más de veinte años de prisión, y sólo 18 a dos años o menos. En cuanto a antropometría, la media de estatura es de 1.64-1.66 metros, y la de peso, 60-68 kilos. Predominan los sujetos de entre 23 y 38 años, y el mayor número relativo se agrupa entre $\operatorname{los} 30$ y los 32 años. Por otra parte, los estudios de genética, en que se investiga el síndorme cromosómico $\mathrm{YY}$, por parte de los doctores Salvador Almendares y Leonora Bueutello, tienen antecedentes en Inglaterra, Estados Unidos y Australia, sin olvidar los estudios sobre gemelos monozigóticos y dizigóticos desarrollados, desde hace cerca de cuatro décadas, por Lange, Legras, Kranz, Strupfl, Rosanoff, Handy y Plessott. 
tesis, algunos de los comentarios que sobre el Centro Penitenciario del Estado de México han formulado expertos mexicanos y extranjeros.

Por to que toca a opiniones de juristas y criminólogos nacionales, consignemos: es un "modelo sin par igual hasta hoy en la República" (Dr. Raúl Carrancá y Trujillo); es ésta "la primera vez que en una prisión mexicana funciona un sistema penitenciario" (Revista Derecho Penal Contemporáneo); es "un Centro Penitenciario modelo que es orgullo de México" (Dr. Juan José González Bustamante); es una obra que "puede orientar a otros penales en la conquista de sus altos objetivos" (Dr. Luis Garrido); "en el Centro Penitenciario del Estado de México se trabaja seriamente, con muy buena orientación técnica" (Dr. Alfonso Quiroz Cuarón); este Centro Penitenciario "es modelo y el primero en la república mexicana con dirección, organización y administración técnicas" (Lic. Javier Piña y Palacios); es el "más adelantado y admirable Centro Penitenciario que existe en el país" (Dr. Samuel Máynez Puente); en el Centro Pe- nitenciario "se cumplen por primera vez en México, los anhelos de una justa política criminal en la ejecución de las penas" (Lic. Luis Fernández Doblado).

En lo que hace a comentarios de expertos extranjeros, el Dr. Julio Altmann Saythe, autor de numerosas obras jurídicas y antiguo Director General de Prisiones del Perú, señala que el Centro Penitenciario "esúnico en la América Latina, un modelo que se debe imitar, ya que se ha situado en una posición de verdadera vanguardia en este campo penitenciario, por sus sistemas, organización, personal, etc.". El Prof. K. O. Shatwall, director de la Facultad de Derecho y del Instituto de Criminología de la Universidad de Sydney, Australia, ha escrito que este Centro es "uno de los mejores que he visto, en cualquier pais. Los programas de trabajo, educación y recreo son excelentes, lo cual se advierte, además, a través de la general ausencia de tensión en la atmósfera de la penitenciaria". Idéntico fue el comentario formulado por el Dr. Israel Drapkin, Director del Instituto de Criminología de la Universidad de Jerusalén. 